\title{
Evaluation of photocatalytic process using GO/ZnO nanocomposites under LED irradiation for removal of Endocrine Disrupting Chemicals (EDCs) from aqueous solutions
}

\author{
Hossieni $\mathrm{S}^{1}$, Sadeghi $\mathrm{S}^{2}$, Saghi $\mathrm{MH}^{3}$, Ghadiri $\mathrm{SK}^{4}$ \\ 1. MSc Student of Environmental Health Engineering, Student Research Committee, Sabzevar University of Medical \\ Sciences, Sabzevar, Iran. ORCID ID: 0000-0003-1450-6064 \\ 2. MSc of Environmental Health Engineering, Spiritual Health Research Center, Research Institute for Health Development, \\ Kurdistan University of Medical Sciences, Sanandaj, Iran. \\ 3. Assistant Professor of Environmental Health Engineering, Non-Communicable Diseases Research Center, Sabzevar \\ University of Medical Sciences, Sabzevar, Iran (Corresponding Author), Tel: +98-05144018319, Email: saghi9@gmail.com, \\ ORCID ID: 0000-0003-1802-7546 \\ 4. Assistant Professor of Environmental Health Engineering, Department of Environmental Health Engineering, School of \\ Public Health, Shahroud University of Medical Sciences, Shahroud, Iran.
}

\begin{abstract}
Background and Aim: Endocrine Disrupting Chemicals (EDCs), and potential EDCs are mostly man-made, found in various materials such as pesticides, metals, additives or contaminants in food, and personal care products. Phthalates are a group of these compounds that are carcinogenic to animals and can cause fetal death and congenital anomalies. The aim of this study was to investigate the photocatalytic process using $\mathrm{GO} / \mathrm{ZnO}$ nanocomposites under LED irradiation for removal of Endocrine Disrupting Chemicals (EDCs) from aqueous solutions.

Materials and Methods: In this study, $\mathrm{GO} / \mathrm{ZnO}$ nanorods were characterized by, Field emission scanning electron microscopy, transmission electron microscope, and Brunauer-Emmett-Teller surface area analysis. A Central Composite Design was used to optimize the reaction parameters for the removal of DEP by $\mathrm{GO} / \mathrm{ZnO}$. The four main reaction parameters optimized in this study were the following: the LED radiation time, $\mathrm{pH}$, and the initial concentration of phthalates and the concentration of $\mathrm{ZnO}$ and graphene-oxide. The interaction between the four parameters was studied and modeled using the Design Expert 10 software. Phthalate detected by HPLC apparatus equipped with a UV detector at $225 \mathrm{~nm}$ wavelength with methanol (90\%) and Acetonitrile (10\%) phases.

Results: The results of FE-SEM and TEM showed that the $\mathrm{ZnO}$ is composed of a bar and separate face. Based on the peak obtained, the diameter and length of the nanorods are 20-60 and $200 \mathrm{~nm}$ respectively. A maximum reduction of $90 \%$ of DEP was achieved at $\mathrm{pH} 5$ and 120 minutes. The results represent the prediction of a model fitted from the Quadratic model ( $p$-value $<00001$ ).

Conclusion: The interaction of variables showed that the maximum effect was belonged to the $\mathrm{pH}$ and the time in the process reactions. Also, the results showed that the GO/ZnO low power LED irradiation can be used as an effective method for the removal of EDCs from environmental.

Keywords: Endocrine Disrupting Chemicals, Photocatalytic, Aqueous solutions, Graphene-oxide, Nanocomposite.
\end{abstract}

Received: June 19, $2019 \quad$ Accepted: July 9, 2019

How to cite the article: Hossieni S, Sadeghi S, Saghi MH, Ghadiri SK. Evaluation of photocatalytic process using $\mathrm{GO} / \mathrm{ZnO}$ nanocomposites under LED irradiation for removal of Endocrine Disrupting Chemicals (EDCs) from aqueous solutions. SJKU 2019;24(4):1-9.

Copyright (C) 2019 the Author (s). Published by Kurdistan University of Medical Sciences. This is an open access article distributed under the terms of the Creative Commons Attribution-Non Commercial License 4.0 (CCBY$\mathrm{NC}$ ), where it is permissible to download, share, remix, transform, and buildup the work provided it is properly cited. The work cannot be used commercially without permission from the journal. 


\title{
بر برى فر آيند فوتوكاليستى نانوكاميوزيت روى اكسيد و اكسيد كر افن تحت تابش براى حذف مختل كنندههاى غدد درون ريز از محلولهاى آبى
}

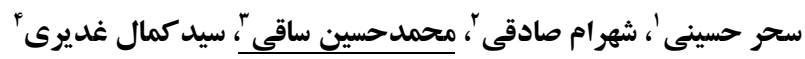

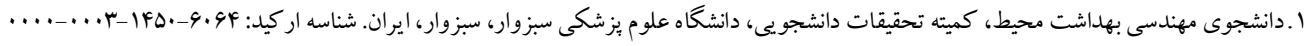

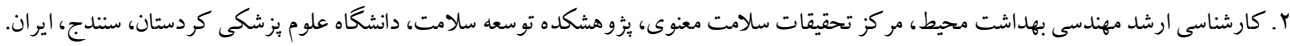

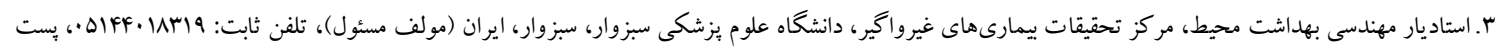

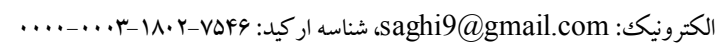

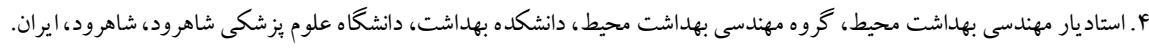

جְكيده زمينه و هدف: تر كيبات مختل كننده غدد درون ريز يك گروه از آلايندهاى خطرناك و بيجيدهى هستند كه در صنعت

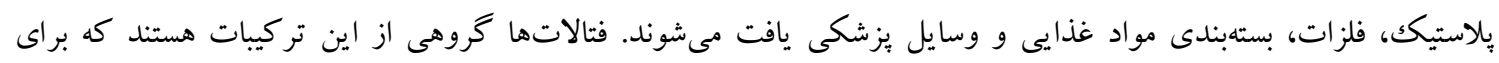

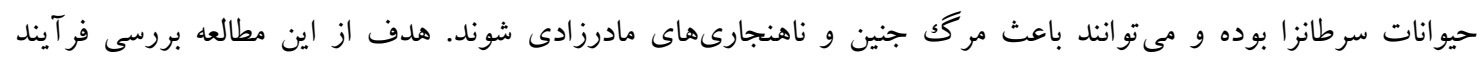

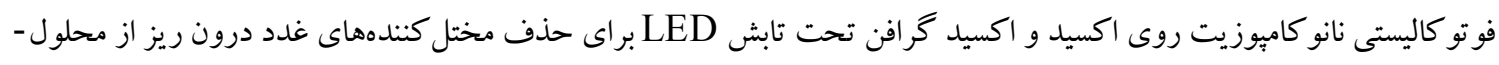
هاى آبى مىباشد.

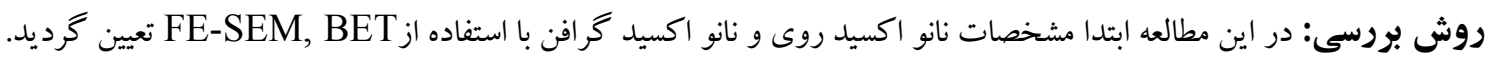

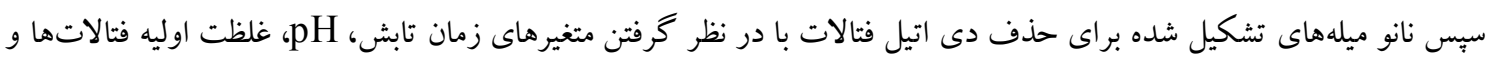

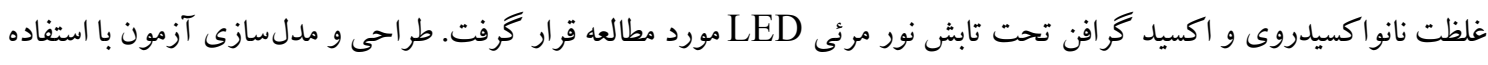

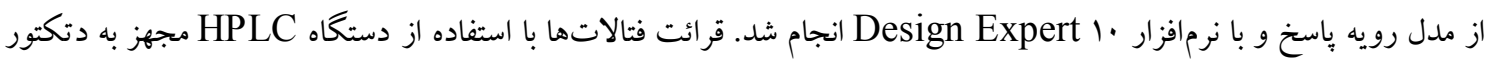

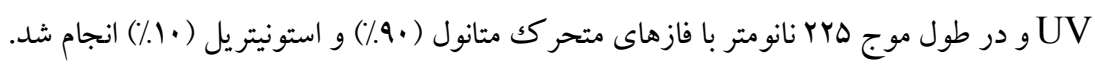
يافته ها: نتايج TEM و FEM نشان داد كه نانو اكسيدروى صورت ميلهاى و مجزا تشكيل شدهاند. بر اساس بيكك

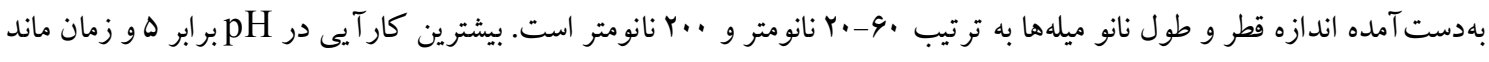

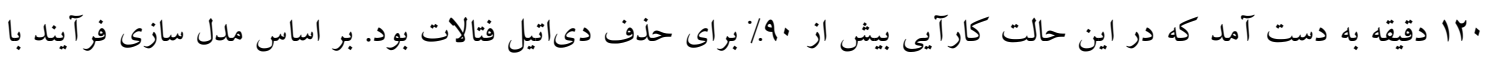

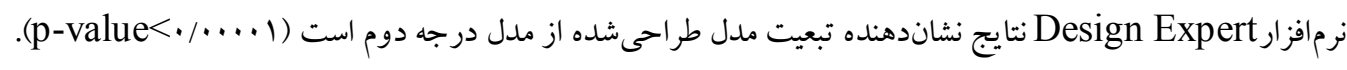
نتيجه كيرى: نتايج حاصل از متغيرها نشان مىدهد كه pH و زمان تماس اثر بيشترى در كار آيى فر آيند دارند. نانو ساختار

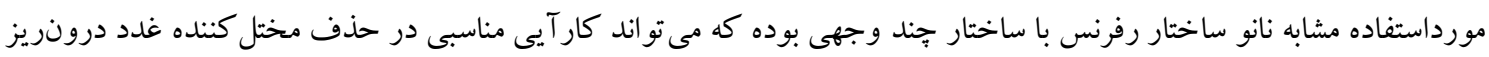

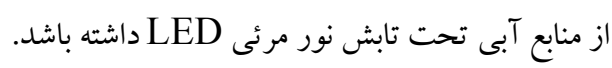

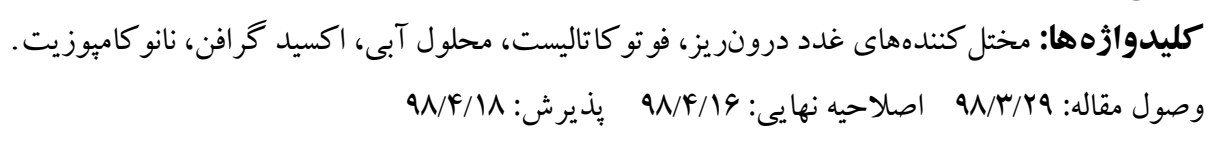


كرده است. بهطور كلى فر آيندهاى اكسيداسيون بيشـرفته در

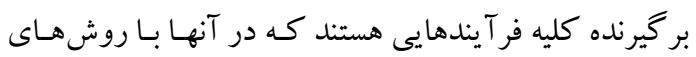

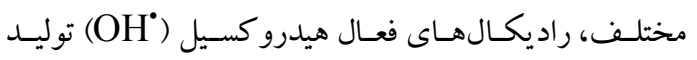

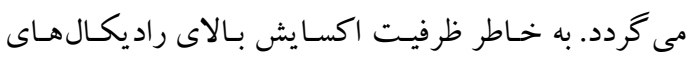

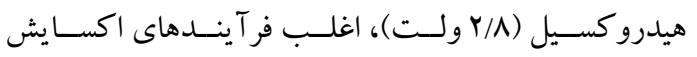

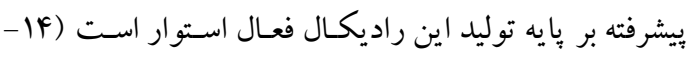

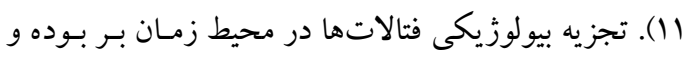

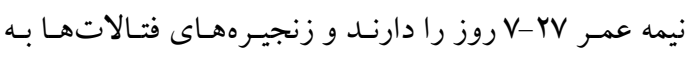

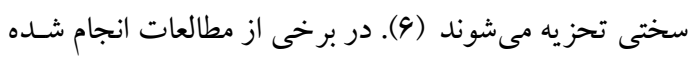

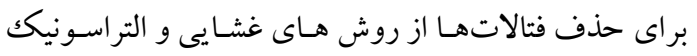

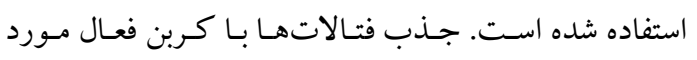

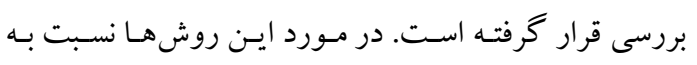

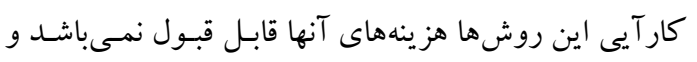

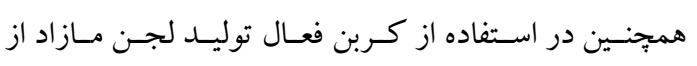

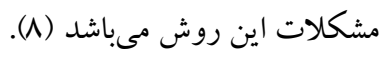

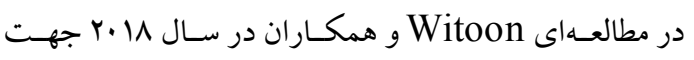
آصلاح نانو اكسيد روى و افزايش خاصيت فو تو كات التيستى

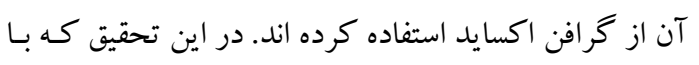

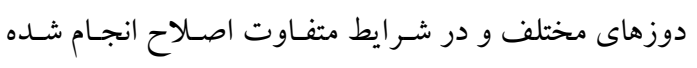

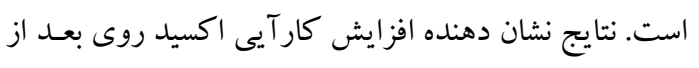

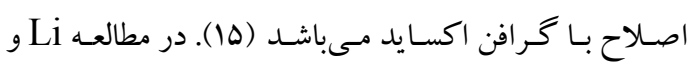

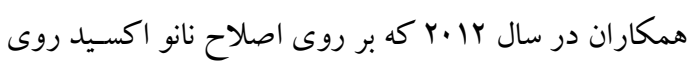

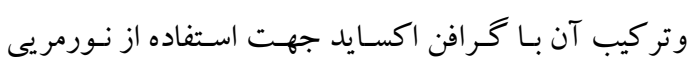
براى فعالسازى خاصيت كاتاليستى نـانو اكسيد روى انس انجـام

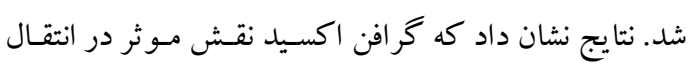
الكترون و كاهش كاف انرزى نانو اكسيد روى دارد (19).

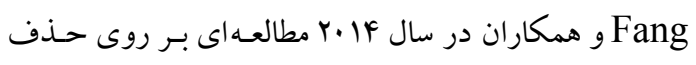

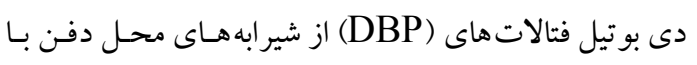

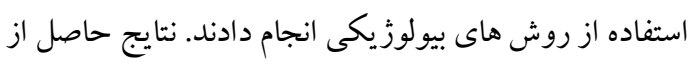

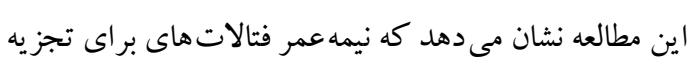

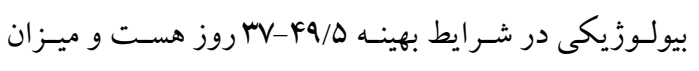

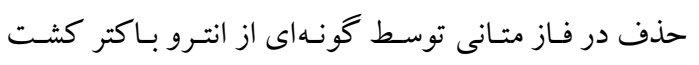

مقدمه

امروزه با توجه به افزايش روزافزون جمعيت، توليـد مـواد

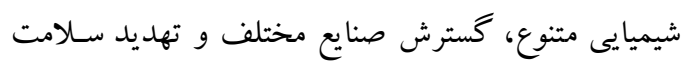
اكوسيستمهـا و موجـودات زنــه از جمله انسـان، مسئله

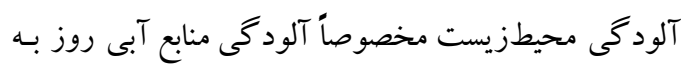

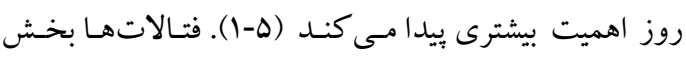

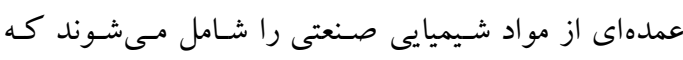

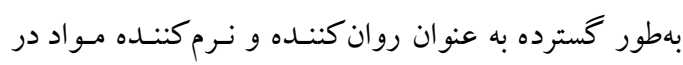
صنايع مختلف استفاده مىشود. توليد رزينهاى بلى وينيل كلريد (يى وى سى) جسبها و رنگكثهاى مختلف از ساير

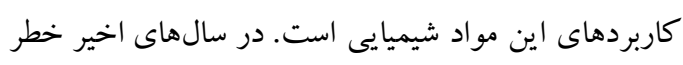

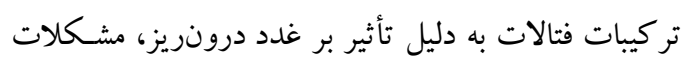

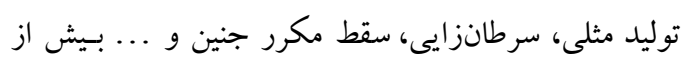

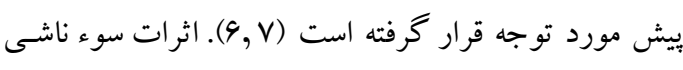
از تماس با فتالاتها در بسيارى از مطالعات به اثبـات رسيده فرونه

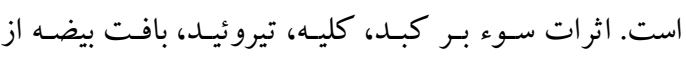

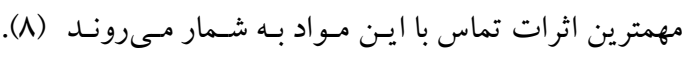

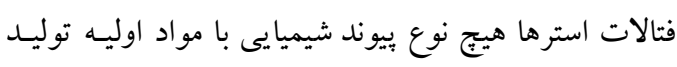

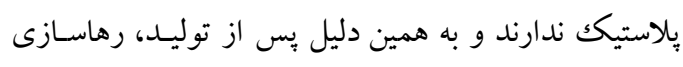

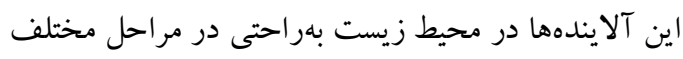
توليد، توزيع، حمل و نقل استفاده و ... انجام مىشود (A).

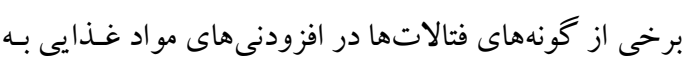
صورت غيرمستقيم مشاهده شده است. در بسته بنـدى مـواد -

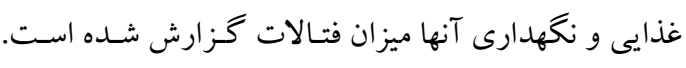

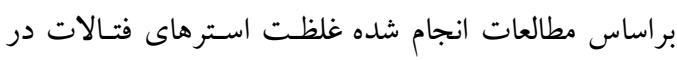

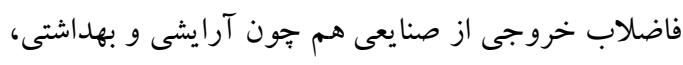

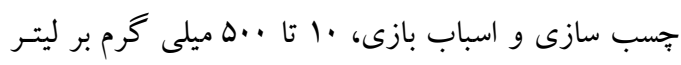
كز ارش شده است (• (9, ج). فناورى فتواكسيداسيون بيشرفته در دهلهاى اخير توسعه قابل

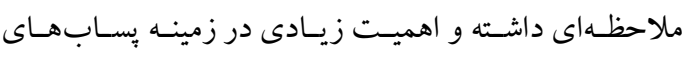

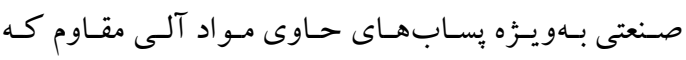

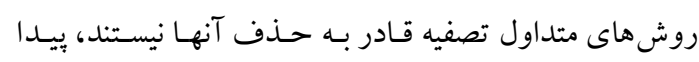


Zn به . له ميلى ليتر از آب مقطر اضافه

شد. محلول آمونيـاك (ها؟) بـراى رسـاندن pH بـه حـدود ه/ه مورد استفاده قرار مى گيرد. بـ از اين مرحلـه نمونسه بـهـ

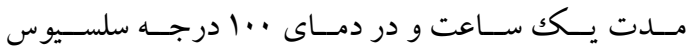
رفلاكس، براى تأمين دماى يكنواخت از قرار دادن بـالن در داخل ظرف روغن بـر روى هيتـر استفاده گرديــ و در ايـن

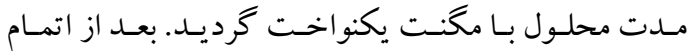
رفلاكس، نمونه در زيـر هـود خنكك شـده تـا رسويات نيز

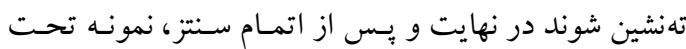

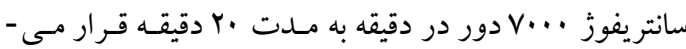
كيرد. مو اد جامد به دست آمده در .ادرجـه بـه مـدت ساعت در آون خشك شده و نهايتا براى ب ساعت در دمـاى

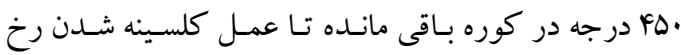

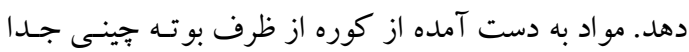
گرديده و در دماى آزمايشگاه نكهدارى مىشدند (.r).

\section{طراحى آزمون}

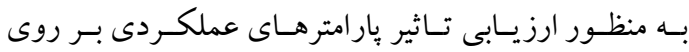

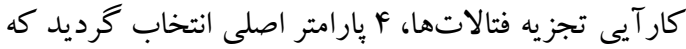

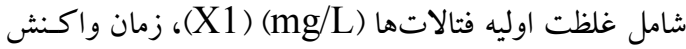
(دقيقـه) (X2)، و (X3 ) pH غلظـت اوليـه اكسـيد روى و اكسيد گر افن (X4) مىباشد. براى حذف دى اتيل فتالات با

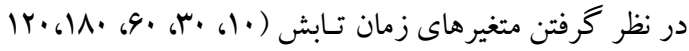

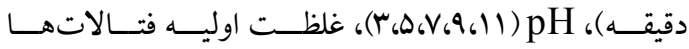

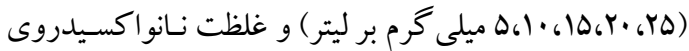

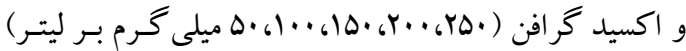
تحت تابش نور مرئى LED مورد مطالعه قرار گرفت. اندازه تيرى دى اتيل فتالات براى اندازهيرى دو نوع فتـالات از دستخكاه HPLC مـدل

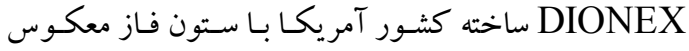
UV-VIS با اندازه C18 OCD در طول موج ·بץ نانومتر استفاده شد. فازهاى متحر كك براى

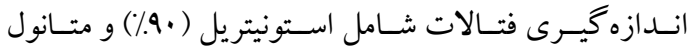

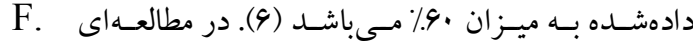

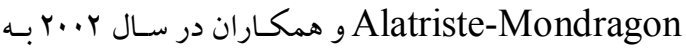
تجزيسه بيولـوزيكى DEHPو DBP بـا استفاده از هضـم بى هو ازى براى تصفيه لجن هاى تصفيه خانه فاضلاب و ميزان

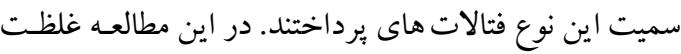

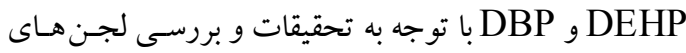

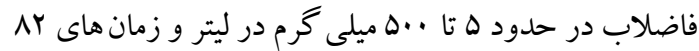
روز ساعت تا •la روز براى تجزيه در نظر گرفته شـد (IV).

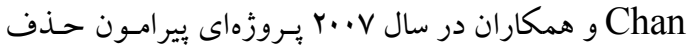
دى اتيل هكزيل فتالات از محلولهاى آبى بـه روش فوتو -

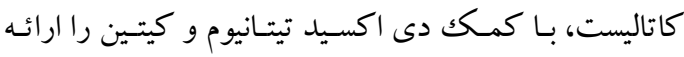

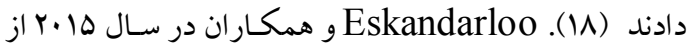
تابش لامب LED جهت فعالسازى نانو اكسيد تيتانيوم براى حذف آلايندههاى زيست محيطى استفاده كرده انــ (19). هـدف از انجـام ايـن طـرح بررسى ميـزان حـذف دئ دى اتيـل

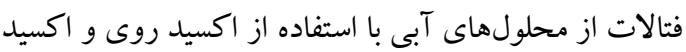

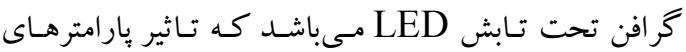
همزمان با استفاده از مدل رويه-بهاسخ بررسى شده است.

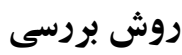

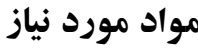
اين مطالعه در مقيـاس آزمايشـكاهى در دانشـكده بهداشـت دانشكاه علوم يزشكى سبزوار انجام شد. مواد به كار رفته در

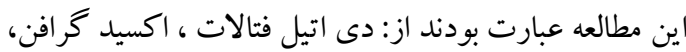

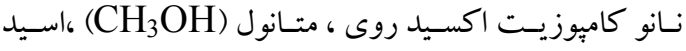

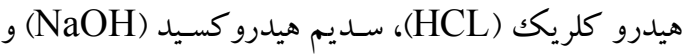
اسـتونيتريل. همـهـ مـو ارد مـورد اسـتفاده در ايسن مطالعه از شركت Merck آلمان تهيه شده اسـت. بـراى تهيـه محلول هورد هاى سـنتيكك DEP از آب دوبـار تقطير استفاده گرديـــ محلول هاى مـورد آزمايش بـا اسـيد هيـدرو كلريكك و pH سديم هيدرو كسيد //ثنرمال تنظيم شد.

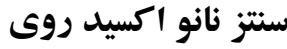
بــراى ســنتز نــانو اكســيدروى از روش ارزان، ســاده و در

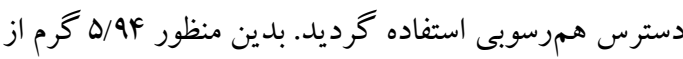

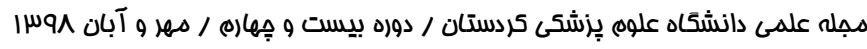




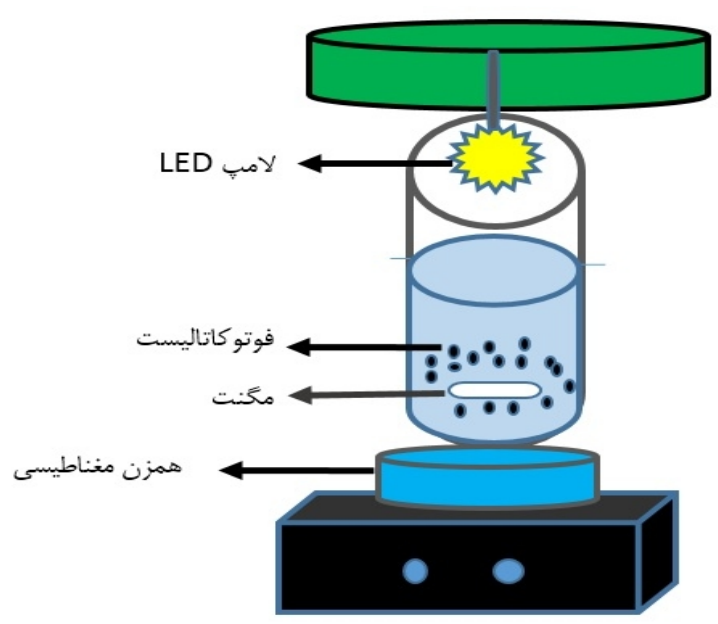

شكل 1: شماتيك يايلوت سيستم ناييوسته مورد استفاده در تحقيق

يافته ها

آزمون تعيين سطح ويزه

براى تعيين سطح ويثه و تعيين خلل و فـرج نـانو مـواد سـنتز

شـده و همجنــين رفتـار جـذب و واجـذب نـانو كامِوزيــت

نمـودار جـــب و واجـذب از نمـودار نـوع ب جـــب تبعيـت

مى كند. همجِنين بر اساس ايسن آنـاليز سـطح تخلخـل

IV/V9

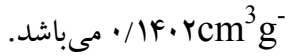

Tآناليز

FE- براى بررسى سـاختار ظـاهرى و انـدازه نـانو ميلـهــا

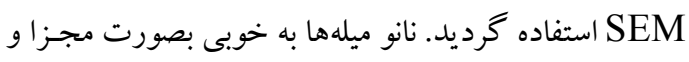

جدا از يكديخر سنتز شدهاند همجنـين شـكل ظـاهرى آنهـا

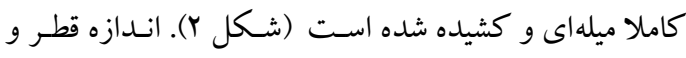

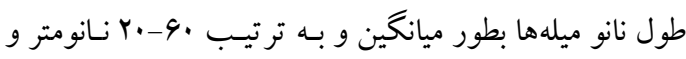

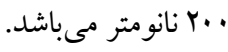

HPLC

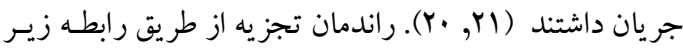

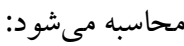

$$
E(\%)=\frac{\left(C_{0}-C_{e}\right)}{C_{0}} \times 100
$$

كه در اين رابطه Ce Ce غل غلظت فتالاتها قبل و بعد از اكسيداسيون مىباشد ظرفيت جذب با استفاده از رابطه زير

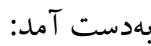

$$
\mathrm{q}_{\mathrm{e}}=\frac{\left(\mathrm{C} \cdot \mathrm{C}_{\mathrm{e}}\right) \mathrm{V}}{\mathrm{M}}
$$

كه در اين رابطه، qu مقدار جزء جذب شده در واحسد جـرم

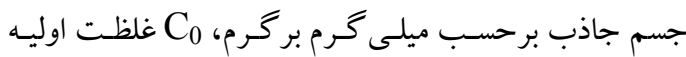

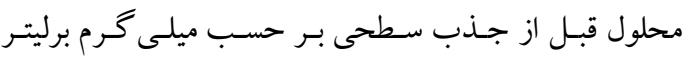

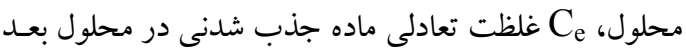
از جذب سطحى برحسب ميلى گرم بر ليتر، V حجم محلول برحسب ليتر و M جرم جاذب برحسب گرم استـ. راكتور

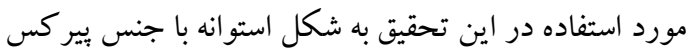

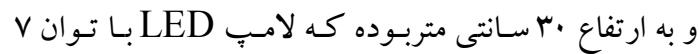

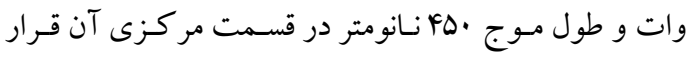

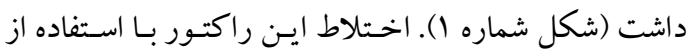
همزن معناطيسى انجام مى شد (r). 

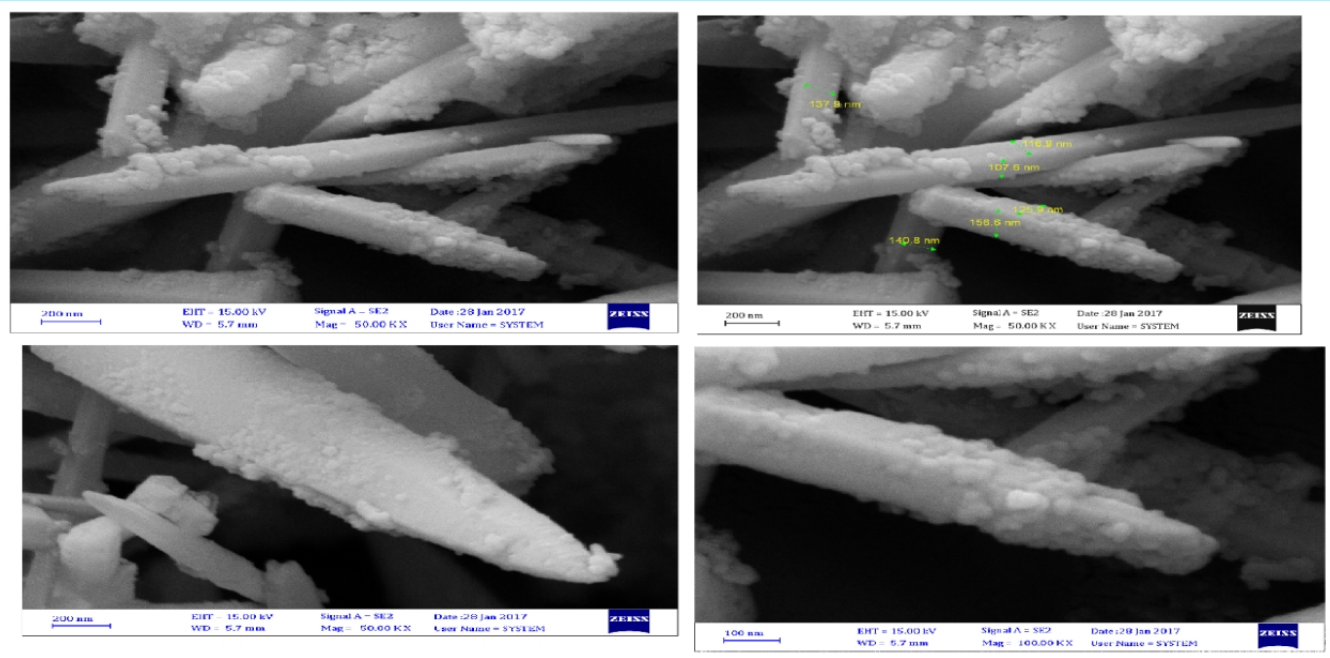

شكل r: تصوير FE -SEM نانو ميله هاى ZnO

\section{بروسى خصوصيات اكسيد كر افن:}

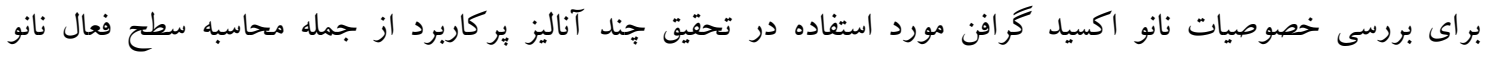

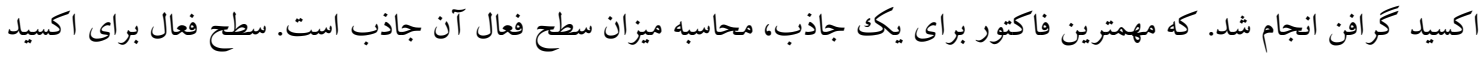

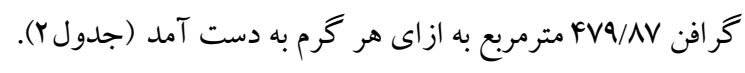

جدول r: سطح فعال نانو بيو گرافن

\begin{tabular}{|c|c|c|}
\hline \multicolumn{2}{|c|}{ سطح فعال نانو گر افن (متر مربع بر گرم) } & \multirow{2}{*}{ ذماى فعالسازى } \\
\hline ميانگين سه آزمايش & نمونه در دسترس & \\
\hline
\end{tabular}

$F \wedge 9 / 9 V \pm 9 / V Y$

$\mathrm{FVq} / \mathrm{AV}$

$\mathrm{V} \wedge \mathrm{V} / 99$

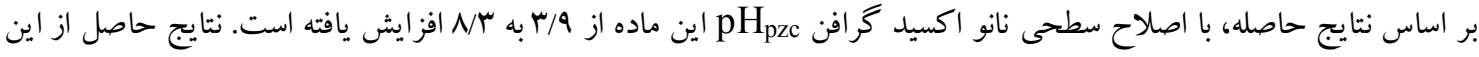

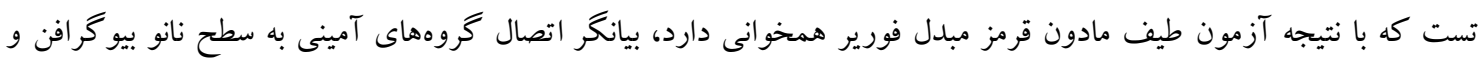
تشكيل يك مبادله كننده آنيونى مىباشد. 

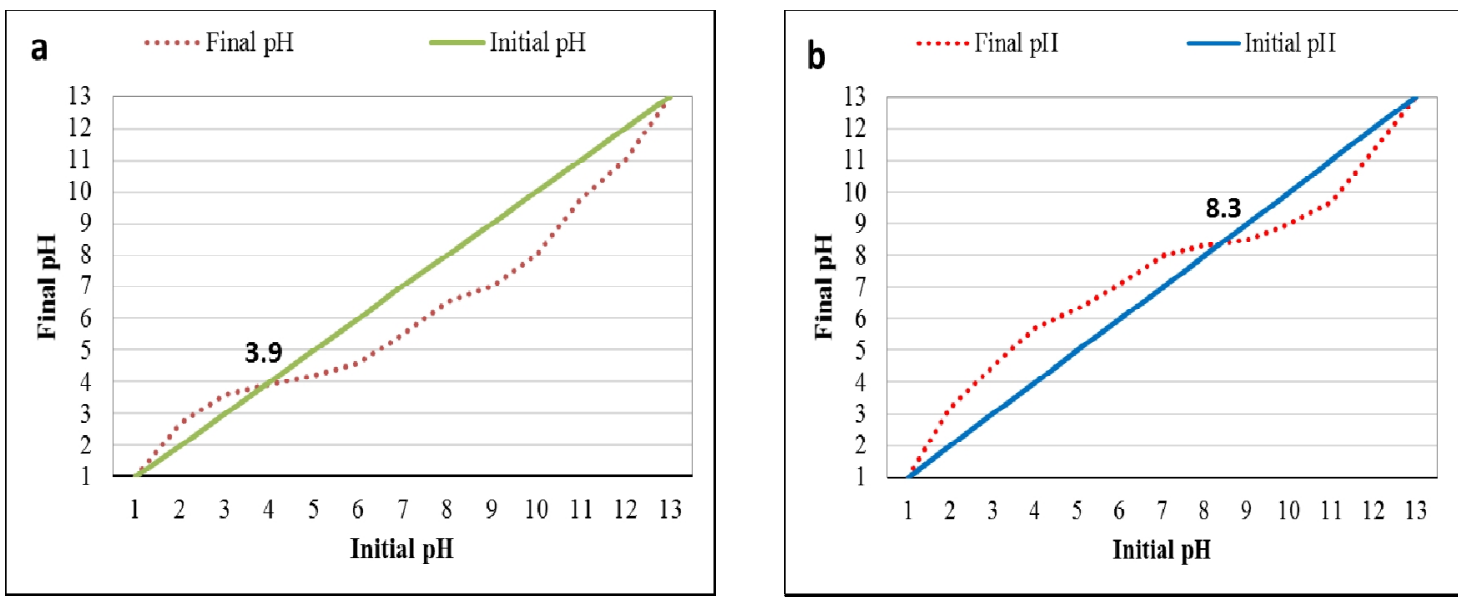

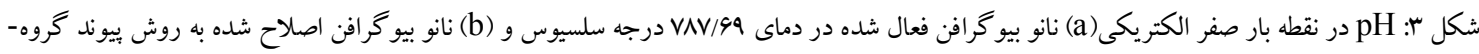
هاى آمينى.

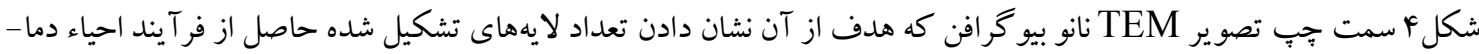
شيميايى مىباشد. به همين منظور تصاوير TEM با بزر گتمايىهاى مختلف و از زواياى مختلف ار ايه شده است.
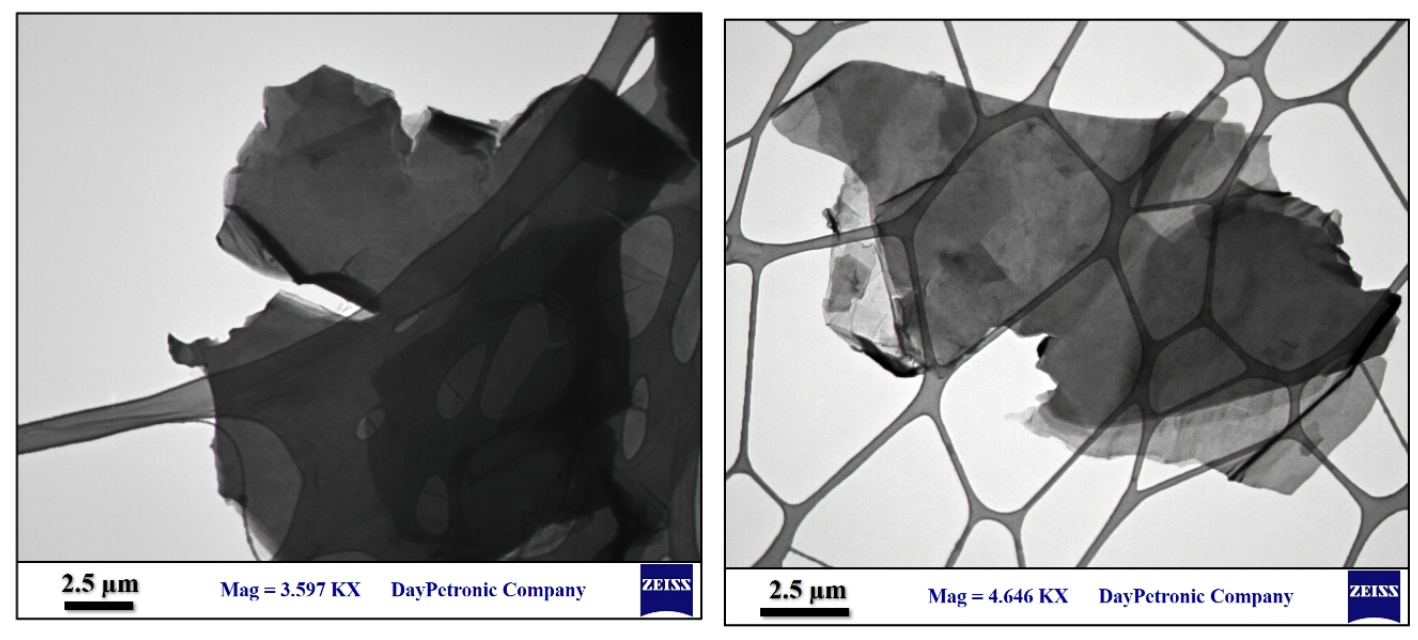

شكل F: TEM اكسيد گرافن مورد استفاده جهت حذف EDC

متغيرها هم نشان ميدهد كـه مقـدار دوز اوليسه كاتاليست و و زمان ماند در مدل معنى دار است.
آناليز RSM جهت تجزيه و تحليل متغيرهاى پاسخ بر اسـاس آنـاليز واريـانس كـه در جـدول بـشــان داده شـده است. مدل معنىدار بود مىباشد و متغيرهـاى غلظت اوليـه، دوز و زمان واكنش تاثير معنىدارى داشتهانـد. بـر همكسنش 


$$
\text { جدول rّ: جدول آناليز واريانس جهت حذف EDC با استفاده از نانو اكسيد روى و اكسيد گرافن }
$$

\begin{tabular}{|c|c|c|c|c|c|c|}
\hline \multirow{3}{*}{$\begin{array}{l}\text { Sum of } \\
\text { Source }\end{array}$} & \multirow{3}{*}{ Squares } & \multirow{3}{*}{$\begin{array}{l}\text { Mean } \\
\mathrm{df}\end{array}$} & \multirow{3}{*}{$\begin{array}{l}\text { F } \\
\text { Square } \\
\text { If }\end{array}$} & \multirow{3}{*}{$\begin{array}{l}\text { p-value } \\
\text { Value }\end{array}$} & \multirow{2}{*}{\multicolumn{2}{|c|}{ Prob $>$ F }} \\
\hline & & & & & & \\
\hline & & & & & m/vi & $<\cdot \cdots \cdot \mid$ \\
\hline A-pH &.$/ \cdot 1 r$ & 1 &.$/ \cdot 1 r$ & $V / r r$ &.$/ 199$ & \\
\hline B-Dose & & $\cdot / \mu F$ & 1 & $\cdot / \mu F$ & IND/AY & $<\cdot / \cdots \cdot$ \\
\hline $\mathrm{C}-\mathrm{C}$ in & &.$/ 1 F$ & 1 & $\cdot / 1 F$ & V9/19 & $<\cdot \cdots \cdot \mid$ \\
\hline D-Time & &.$/ \cdot \mathrm{kr}$ & 1 &.$/ \cdot p r$ & $r M / \Delta F$ & $\cdot \cdots r$ \\
\hline $\mathrm{AB}$ & . & 1 & 1 & $I T / V F$ & $\because \cdot r \Lambda$ & \\
\hline $\mathrm{AC}$ & &.$/ \cdot Y Y$ & 1 &.$/ \cdot Y$ & $|r /|$. & $\% M r$ \\
\hline $\mathrm{AD}$ & & $V / \Lambda \cdot 9 E-. \cdot r$ & 1 & $V / \Lambda \cdot \varphi E-\cdots r$ & $F / Y F$ & $\% \Delta V r$ \\
\hline $\mathrm{BC}$ & & $/ \mu ৭ ৭ E-\cdots \vee V$ & 1 & $r / r q ৭ E-\cdots \vee$ & l/AFsE-..F &.$/ 9194$ \\
\hline $\mathrm{BD}$ &.$/ 11$ & & 1 &.$/ \cdot 11$ & $9 / 10$ & $\cdot / \cdot r \Delta \Delta$ \\
\hline $\mathrm{CD}$ & & 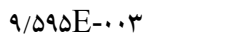 & 1 & $q / \Delta ৭ \Delta E-\cdots r$ & $\Delta / Y)$ &.$/ \cdot \mathrm{MV}$ \\
\hline $\mathrm{A}^{2}$ & & r/grqE-..r & 1 & r/grqE-..r & $r / \Delta 1$ & $\cdot / \cdot m v$ \\
\hline $\mathrm{B}^{2}$ & 洪 & 1 & r & IYG/FT & $<\cdot / \cdots \cdot$ & \\
\hline $\mathrm{C}^{2}$ & & $r / r \cdot \Delta E-\cdots q$ & 1 & $r / r \cdot \Delta E-\ldots q$ & r & . /9rov \\
\hline $\mathrm{D}^{2}$ & & $r / r q \wedge E-. r$ & 1 & $r / r q \wedge E-. . r$ & $1 / \%$. & $\cdot /$ TVIV \\
\hline Residual & &.$/ \cdot \mathrm{r \Lambda}$ & 10 & l/AfrE-..r & & \\
\hline Lack of Fit & &.$/ \cdot r r$ & 1. & $r / r \cdot r E-$ & 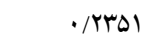 & not significant \\
\hline Pure Error & & $\Delta / \Delta q \cdot E-. \cdot r$ & $\Delta$ & ו/1АE-..r & & \\
\hline Cor Total & & $\cdot / 9$ & rq & & & \\
\hline Std. Dev. &.$/ . \mathrm{kr}$ & & & R-Squared & . /999 & \\
\hline Mean & $\cdot / V$ & & & Adj R-Squared &.$/ 94.9$ & \\
\hline
\end{tabular}


فرمولهاى استخراجى از نرم افزار در زير نشان داده شده است. فرمول نهايى منتج شده از نرم افزار بر اساس متغيرهاى مورد مطالعه به شكل زير مىباشد. $\mathrm{R}=+0.077316-0.088902 * \mathrm{pH}+0.017730 *$ Dose-0.060769 $* \mathrm{C}$ in+9.22536E-004 * Time3.82901E-004 $* \mathrm{pH} *$ Dose+3.73149E-003 $* \mathrm{pH} * \mathrm{C}$ in+3.68121E-004 $* \mathrm{pH} *$ Time$5.83008 \mathrm{E}-007 *$ Dose $* \mathrm{C}$ in-1.77427E-005 $*$ Dose $*$ Time $+1.63260 \mathrm{E}-004 * \mathrm{C}$ in $*$ Time+3.24763E-003* $\mathrm{pH}^{2}-3.68524 \mathrm{E}-005 * \mathrm{Dose}^{2}+1.58470 \mathrm{E}-004 * \mathrm{C}$ in $^{2}-1.03898 \mathrm{E}-005 *$ Time $^{2}$

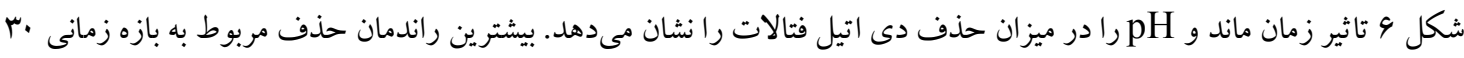

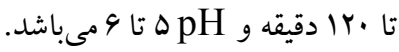

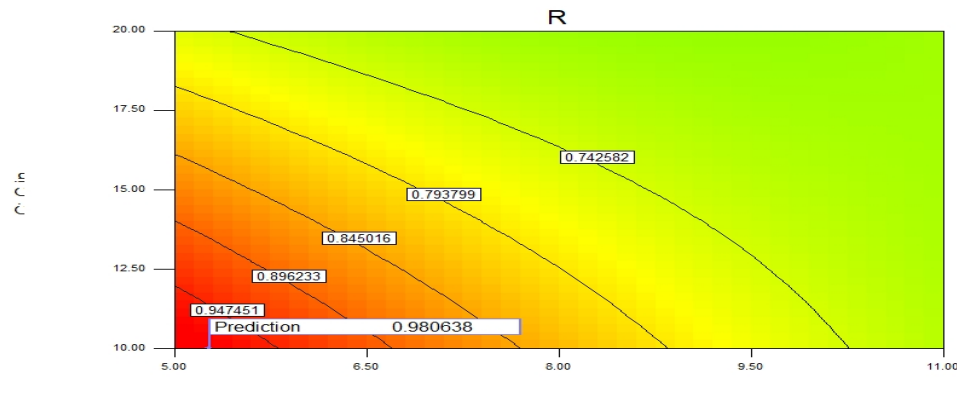

A: $\mathrm{pH}$

شكل 9: تاثير زمان و pH بر كار آيى حذف DEP(غلظت DEP، mg •ه- تحت تابش LED با قدرت Vوات)

در شكل Vاثير ميزان pHو غلظت آلاينده DEP در كار آيى حذف DEP بر رسى شده است. طبق تصوير بيشترين راندمان حذف در محدوده pH بين هـ تا و و غلظت/ mg • ادى اتيل فتالات به دست آمده است.

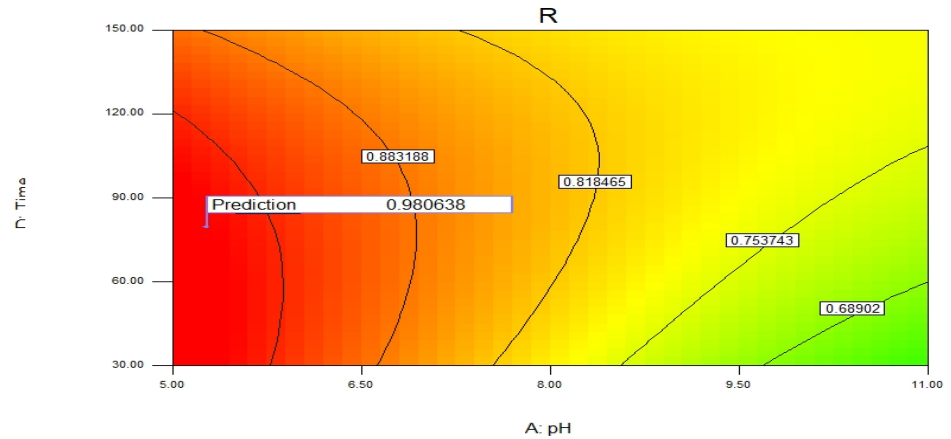

شكل V: تاثير غلظت آلاينده و pH بر كار آيى حذف DEP (غلظت DEP، هo •ه- تحت تابش LED با قدرت Vوات)

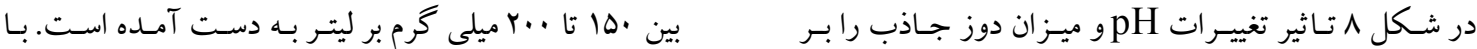

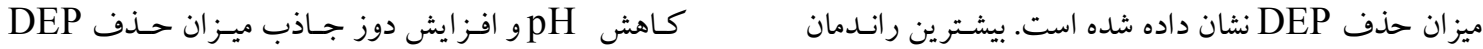

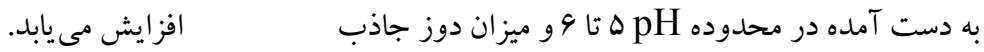




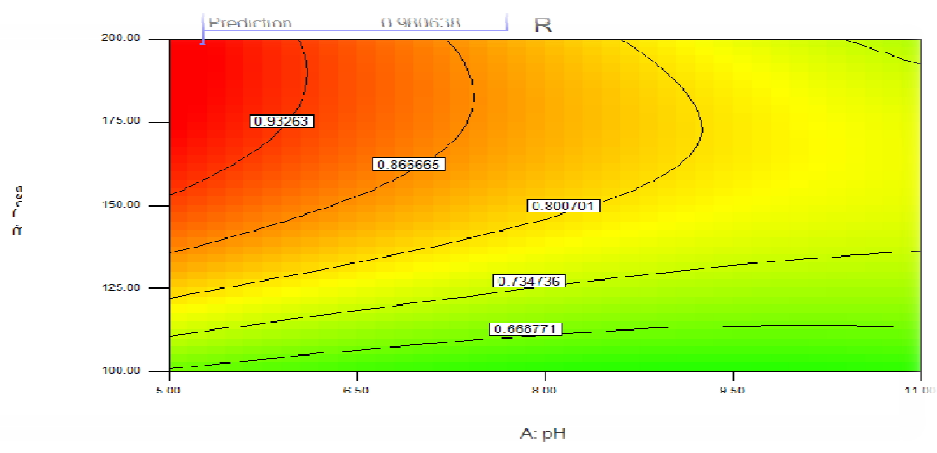

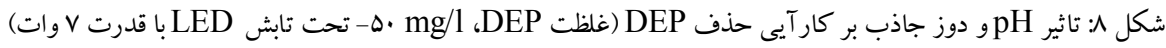

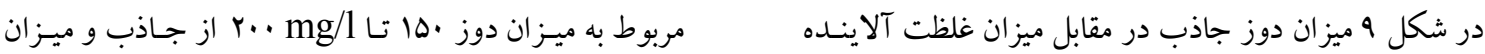

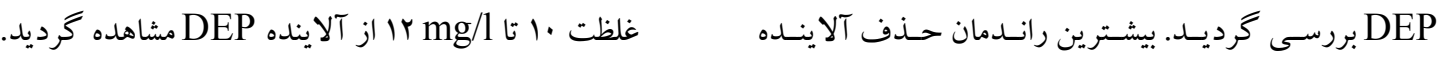

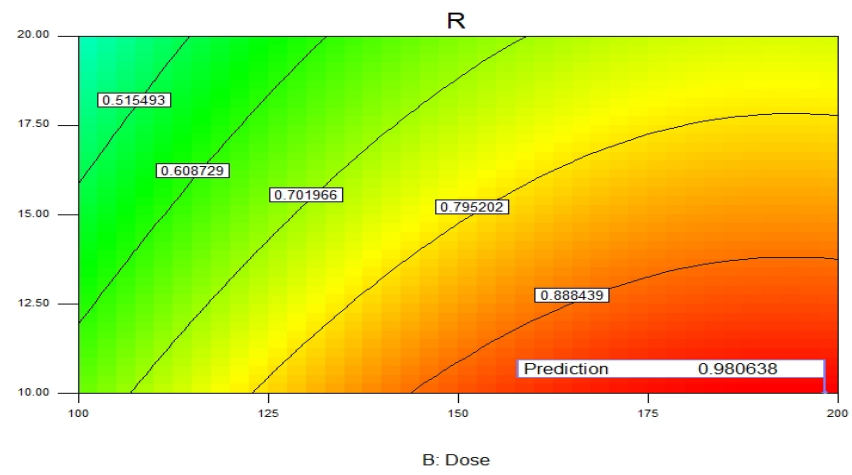

شكل 9: تاثير دوز جاذب و غلظت آلاينده بر كار آيى حذف DEP(غلظت DEP، هـ.mg/1 تحت تابش LED با قدرت Vوات)

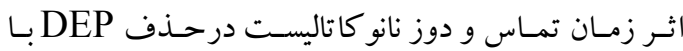

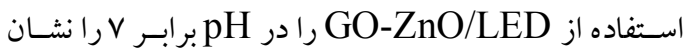

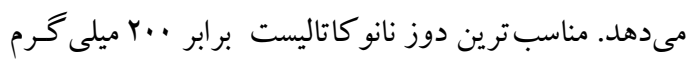
در ليتر انتخاب گرديد.

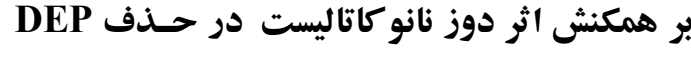

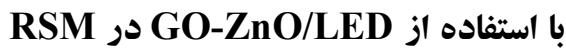

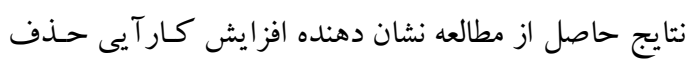

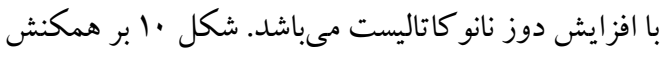

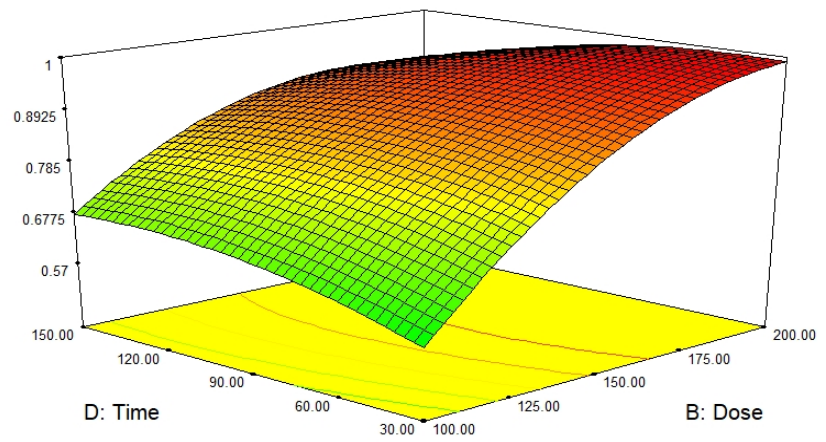

شكل • (: برهمكنش اثر زمان تماس و دوز نانو كاتاليست در حذف DEP با استفاده از GH ) برابر با Vو غلظت اوليه جاذب • ميلى گرم بر ليتر )

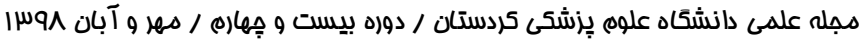


شــده فتـونى منتقـل شـده و در اثـر خـوردگى نسورى ZnO

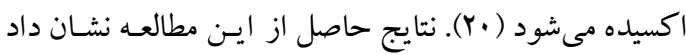

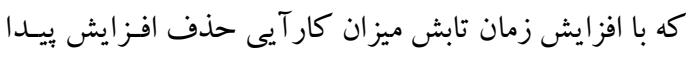

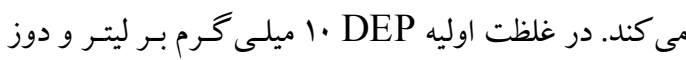

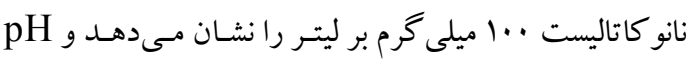

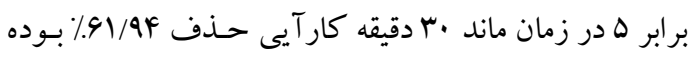

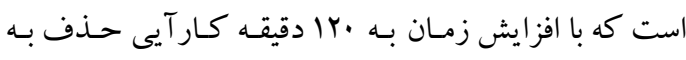

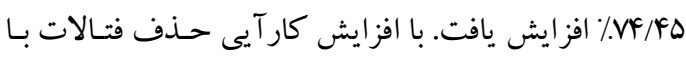

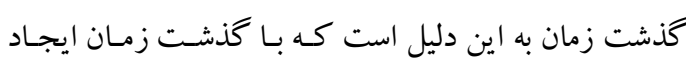

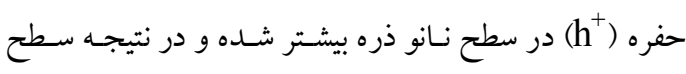
مقطع جذب و كار آيى حذف نيز افزايش مسي ديابــ همجنـين

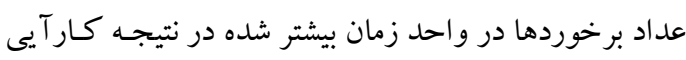
حذف افز ايش مى ميابد (1). مدلهاى مختلف براى تجز يه فتو كاتاليستى دو نوع فتـالات

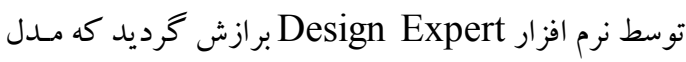
درجه دوم كمترين مقدار p-value را داشت و مناسب ترين مدل بر اساس نتايج آزمايش بود. با توجـه بـه جـدول مدول آنـاليز

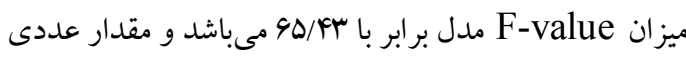

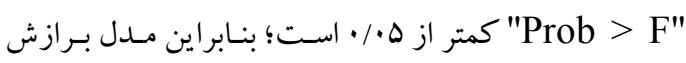

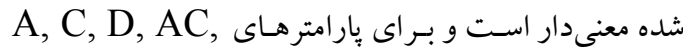
مدل معنى دار مىباشد. نرم افزار مدل درجه دو

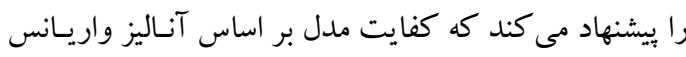

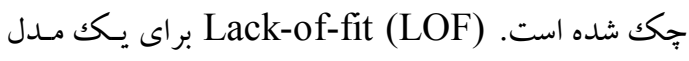
زمانى اتفاق مى افتد كه مدل بصورت مناسب بِ باسخ ميانگين

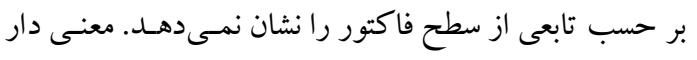

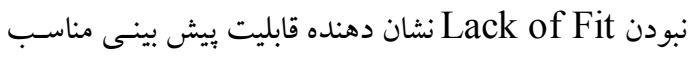
مدل مىباشد؛ كه براى مدل برازش شده در اين تحقيق براى لئى لئس

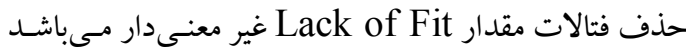

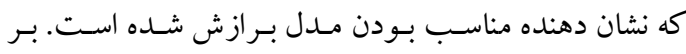

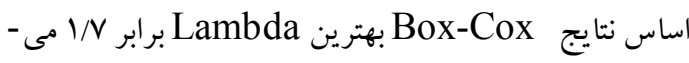
باشد كه در اين مدل برابر ا شده است و نشـان دهنـده معتبر

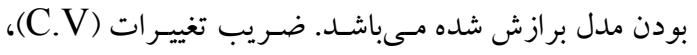

در ابتداى فر آيند جذب با توجه به وجود تعداد زياد مكان هاى جذب، تفاوت زيادى بـين غلظـت مـاده جـذب شـونده موجود در محلول و بر روى سطح جـاذب وجهود دارد. ايسن

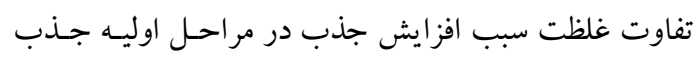

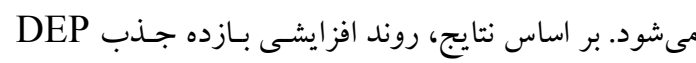

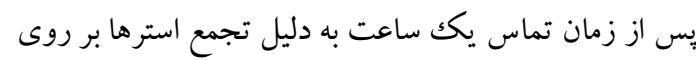

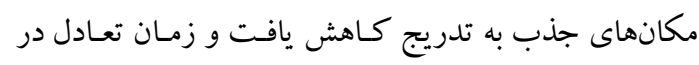

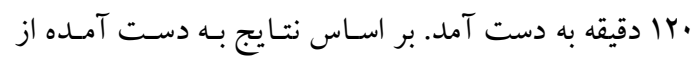

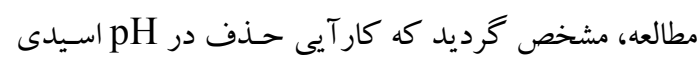

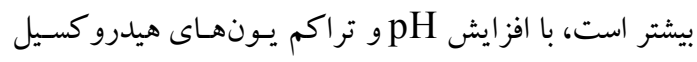

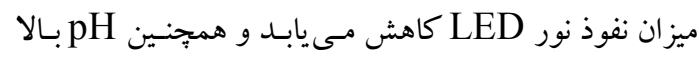
سبب افزايش تشكيل يون كربنات شده كـه اسكاونجر يون

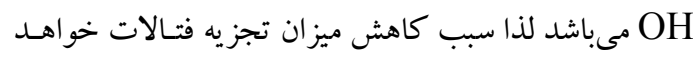
شد (Yr). طى مطالعهاى كه Pardeshi و همكاران در سـال

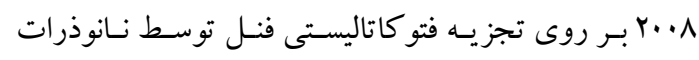

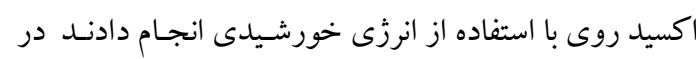

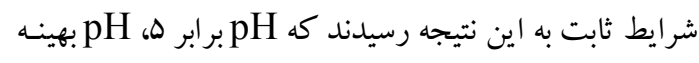

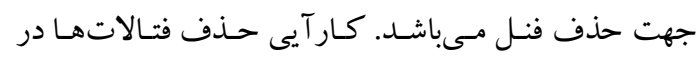

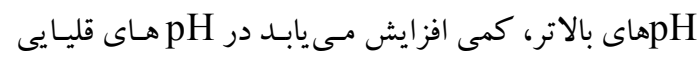

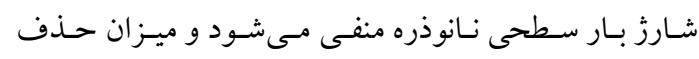

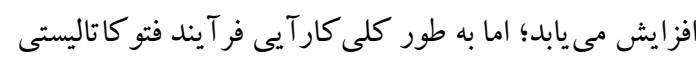

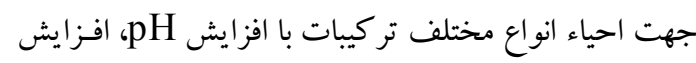

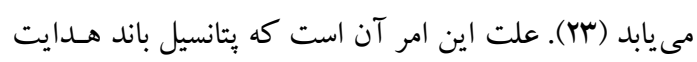

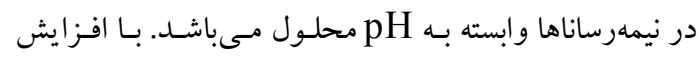

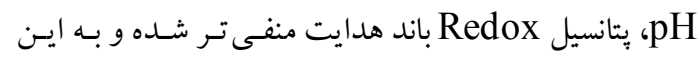

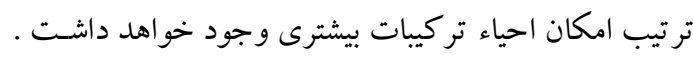

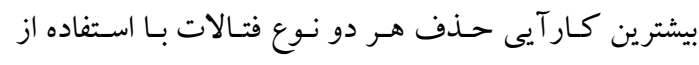

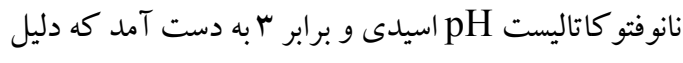

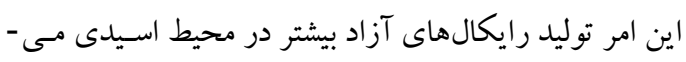

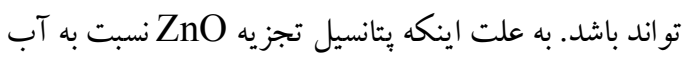

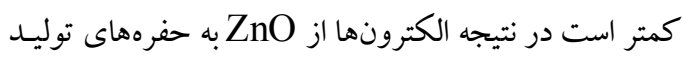




$$
\begin{aligned}
& \text { نسبت خطاى استاندارد تخمين به متوسط مقدار باسـخ بـيش دهنده مناسبودن و كار آمدبودن نانو اكسيد روى و اكسيد } \\
& \text { بينى شده است و به عنوان قابليت تكرار بذيرى مدل تعريف }
\end{aligned}
$$

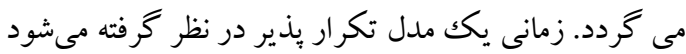

$$
\begin{aligned}
& \text { تشكر و قدردانى } \\
& \text { كه مقدار C.V آن كمتر از · ادرصد باشد (•r). }
\end{aligned}
$$

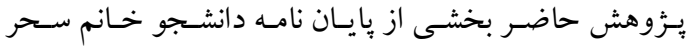

$$
\begin{aligned}
& \text { حسينى مى باشد كه با حمايت مالى معاونت تحقيقـات و فـن }
\end{aligned}
$$

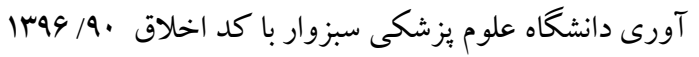

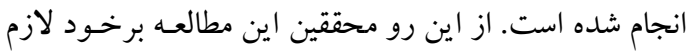

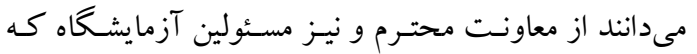

$$
\begin{aligned}
& \text { نهايت همكارى را بر ما داشته انـد تشكر صـميمانه بـه عمـل }
\end{aligned}
$$

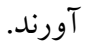

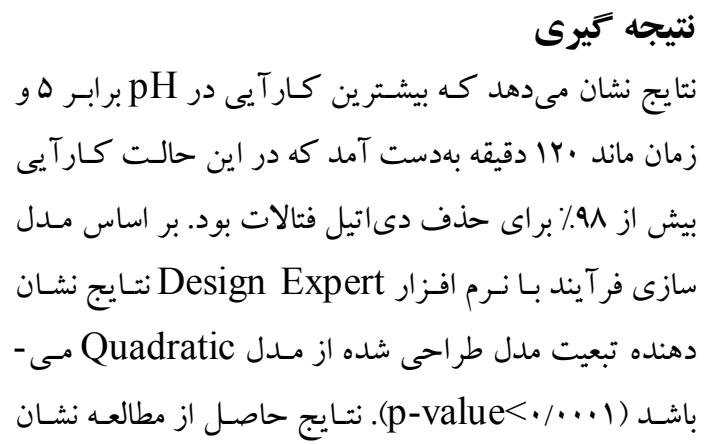

\section{References}

1. Khodadadi M, Al-Musawi TJ, Kamranifar M, Saghi MH, Panahi AH. A comparative study of using barberry stem powder and ash as adsorbents for adsorption of humic acid. Environ Sci Pollut Res 2019;26: 26159-69.

2. Khodadadi M, Saghi MH, Azadi NA, Sadeghi S. Adsorption of chromium VI from aqueous solutions onto nanoparticle sorbent: chitozan-Fe-Zr. J Mazandaran Univ Med Sci 2016; 26: 70-82. [In Persian]

3. Khaniabadi YO, Basiri H, Nourmoradi H, Mohammadi MJ, Yari AR, Sadeghi S, Amrane A. Adsorption of Congo Red Dye from aqueous solutions by montmorillonite as a low-cost adsorbent. Int J Chem React Eng 2018;1:1-11.

4. Mohammadi MJ, Khaniabadi YO, Basiri H, Amrane A, Nourmoradi H, Momtazan M, Sadeghi S, Charkhloo E, Gholami-Borujeni F, Jorfi S, Takdastan A. Montmorillonite as adsorbent for the removal of methyl red from aqueous solution. Fresenius Environ Bull 2017; 26:4088-96.

5. Gholami Z, Ghadiri SK, Avazpour M ,Fard MA, Yousefi N, Talebi SS, et al. Removal of phosphate from aqueous solutions using modified activated carbon prepared from agricultural waste (Populous caspica): optimization, kinetic, isotherm, and thermodynamic studies. Desalination Water Treat 2018;133:177-90.

6. Fang C-r, Long Y-y, Shen D-s. Removal of dibutyl phthalate from refuse from different phases of landfill in the presence of its dominant bacterial strains. Ecol Eng 2014; 71: 87-93.

7. Food and Drug Administration. Safety Assessment of Di (2-ethylhexyl) Phthalate (DEHP) Release from Medical Devices. US Food and Drug Administration, Washington, DC http://wwwfdagov/cdrh/ost/dehp-pvcpd. 2002.

8. Lutterbeck CA, Machado ÊL, Kümmerer K. Photodegradation of the antineoplastic cyclophosphamide: A comparative study of the efficiencies of $\mathrm{UV} / \mathrm{H}_{2} \mathrm{O}_{2}, \mathrm{UV} / \mathrm{Fe}_{2}+/ \mathrm{H}_{2} \mathrm{O}_{2}$ and $\mathrm{UV} / \mathrm{TiO}_{2}$ processes. Chemosphere 2015;120:538-46.

9. Jonsson S, Ejlertsson J, Svensson Bh. Transformation of phthalates in younglandfill cells. Waste Manag 2003;23:641-51. 
10. Kalmykova Y, Moona N, mvall A-MS, rklund KB .Sorption and degradation of petroleum hydrocarbons, polycyclic aromatic hydrocarbons, alkylphenols, bisphenol A and phthalates in landfill leachate using sand, activated carbon and peat filters. Water Res 2014;56: 246 -57.

11. Castro CA, Osorio P, Sienkiewicz A, Pulgarin C, Centeno A, Giraldo SA. Photocatalytic production of $1 \mathrm{O} 2$ and $\mathrm{OH}$ mediated by silver oxidation during the photoinactivation of Escherichia coli with $\mathrm{TiO}_{2}$. J Hazard Mater 2012:172-81.

12. Donkova B. Catalytic and photocatalytic activity of lightly doped catalysts $\mathrm{M}: \mathrm{ZnO}(\mathrm{M}=$ $\mathrm{Cu}, \mathrm{Mn})$. Mater Chem Phys 2010;123:563-8.

13. Gholami M, Farzadkia M, Zandsalimi Y, Sadeghi S, Abouee Mehrizi E. Efficacy of Crdoped $\mathrm{ZnO}$ nanoparticles in removal of reactive black 5 dye from aqueous solutions in presence of solar radiation. J Mazandaran Univ Med Sci 2016; 26: 59-69. [In Persian]

14. Zandsalimi Y, Sadeghi S, Reshadmanesh N, Ghahramani E. Efficacy of photocatalytic removal of chromium in the presence of organic matter from aqueous medium by useing $\mathrm{TiO}_{2}$ nanoparticles synthesized by sol gel. SJKU 2018;22:84-95. [In Persian]

15. Witoon T, Numpilai T, Phongamwong T, Donphai W, Boonyuen C, Warakulwit C, et al. Enhanced activity, selectivity and stability of a $\mathrm{CuO}-\mathrm{ZnO}-\mathrm{ZrO}_{2}$ catalyst by adding graphene oxide for $\mathrm{CO}_{2}$ hydrogenation to methanol. Chem Eng J 2018;334:1781-91.

16. Li B, Liu T, Wang Y, Wang ZJJoc, science i. ZnO/graphene-oxide nanocomposite with remarkably enhanced visible-light-driven photocatalytic performance. J Colloid Interface Sci 2012;377:114-21.

17. Agency for Toxic Substances and Disease Registry (ATSDR). Toxicological profile for Di (2-ethylhexyl) phthalate. Agency for Toxic Substances and Disease: Atlanta, GA; 2002.

18. Chan CM, Wong KH, Chung WK, Chow TS, Wong PK. Photocatalytic degradation of di (2-ethylhexyl) phthalate adsorbed by chitin A. Water Sci Technol 2007 56:125-34.

19. Eskandarloo H, Badiei A, Behnajady MA, Ziarani GM. UV-LEDs assisted preparation of silver deposited $\mathrm{TiO}_{2}$ catalyst bed inside microchannels as a high efficiency microphotoreactor for cleaning polluted water. Chem Eng J 2015;270:158-67.

20. Akbari-Adergani B, Saghi M, Eslami A, Mohseni-Bandpei A, Rabbani MJEt. Removal of dibutyl phthalate from aqueous environments using a nanophotocatalytic Fe, Ag-ZnO/VISLED system: modeling and optimization. Environ Technol 2018;39:1566-76.

21. Yuliya K, Moona N, Stro“mvall A-M, Bjo“rklund K. Sorption and degradation of petroleum hydrocarbons, polycyclic aromatic hydrocarbons, alkylphenols, bisphenol A and phthalates in landfill leachate using sand, activated carbon and peat filters. Water Res 2014; 56:246-57.

22. Eslami A, Akbari-Adergani B, A M-B, Rabbani M, MH. S. Synthesis and characterization of a coated Fe-Ag@ ZnO nanorod for the purification of a polluted environmental solution under simulated sunlight irradiation. Mater Lett 2017;197:205-8.

23. Pardeshi SK, Patil AB. A simple route for photocatalytic degradation of phenol in aqueous zinc oxide suspension using solar energy. Sol Energy 2008;82:700-5. 